\title{
The use of 3D scanning for the inventory of historical buildings on the example of the palace in Snopków
}

\author{
Karol Krupa \\ https://orcid.org/0000-0002-7313-4080 \\ k.krupa@pollub.pl
}

\section{Piotr Gleń}

https://orcid.org/0000-0002-2975-408X

p.glen@pollub.pl

Faculty of Civil Engineering and Architecture, Lublin University of Technology

\begin{abstract}
This paper discusses the use of modern technology of inventory measurements based on the inventory of the historical palace and park complex in Snopków. The inventory of the site was made using laser scanning measurements. The article draws attention to the specificity of the inventory of historical sites, their complexity and diversity of architectural details that are important for proper revitalisation and further preservation works.
\end{abstract}

Keywords: palace and park complex, Snopków, 3D scanning, inventory, point cloud, monument

\section{Introduction}

Architectural inventory concerning the protection of monuments requires mapping of the appearance of a historical structure in the most accurate way, both in the graphic and text form [Filipowski 2018]. The site covered by this study is located in the palace and park complex in Snopków near Lublin. The palace was built in the 1880 s as a residential manor. It was entered into the register of monuments of the Lublin Province on 16 October 1971 [Decision 1971]. Content of the entry:

The palace and park complex in Snopków, the district of Lublin, within the borders marked on the map. The complex consists of: a brick one-storey palace, probably built before the $19^{\text {th }}$ century, rebuilt at the turn of the $19^{\text {th }}$ and $20^{\text {th }}$ centuries with its full architectural decoration originating from the period of reconstruction, as well as a landscape park with a regular, readable part of the old baroque layout, connecting in terms of view and composition with the Dys river flowing on its edge, which originally was spreading into picturesque ponds. Justification for the entry: The palace and park complex in Snopków is an example of the representative architectural complexes dating back to the Baroque epoch; the park with a preserved tree stand of more than 300 years is of particular value. (Fig. 1.)

The works carried out at the above-mentioned facility included a detailed inventory of the palace building based on a point cloud obtained from measurements with a Leica C10 laser scanner. The inventory carried out in this technology consists of detailed measurement information, architectural detail, wall curvature, roof geometry, ceiling deflection and deformation of the wooden roof truss over the years. The model of the site created with specialised software may be useful in a number of later works planned by the conservator of the site [Kulig 2015]. 


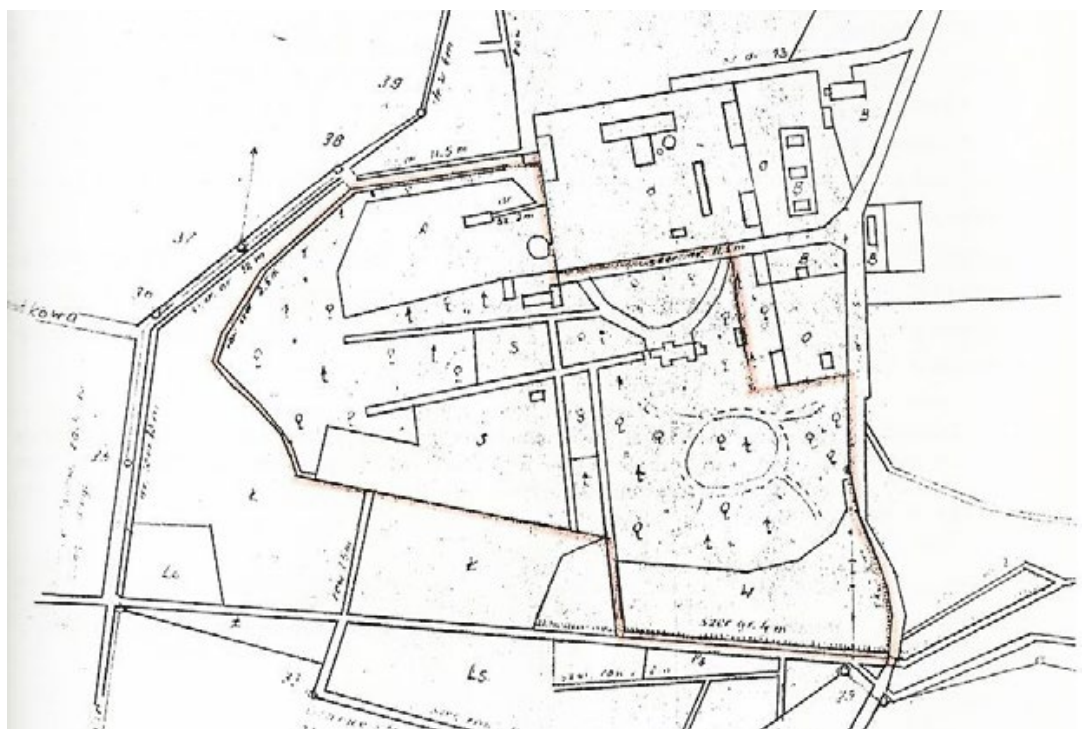

Fig. 1. The annex to the decision on entry into the register of monuments of the Lublin Voivodeship No. KL-IV_7/3/71 of 16 October 1971. Source: Composition and Plan View of the garden in the Palace and Park Complex in Snopków.

\section{The characteristics of the site}

The palace building has a basement under a part of its surface built on the plan of the letter " $U$ " with a multi-sloped roof. The plan of the building is composed of segmented rectangles, with the two-storey central part with an unusable attic and one-storey side wings with usable attics. Outermost east two-storey wing has lowered ground floor level. The second floor of the east wing is not connected with the palace floor. On the south side, there is a semi-circular terrace with three-run concurrent stairs. The main body of the palace on the east side is crowned with a clock tower with a tented roof. (Fig. 2.)

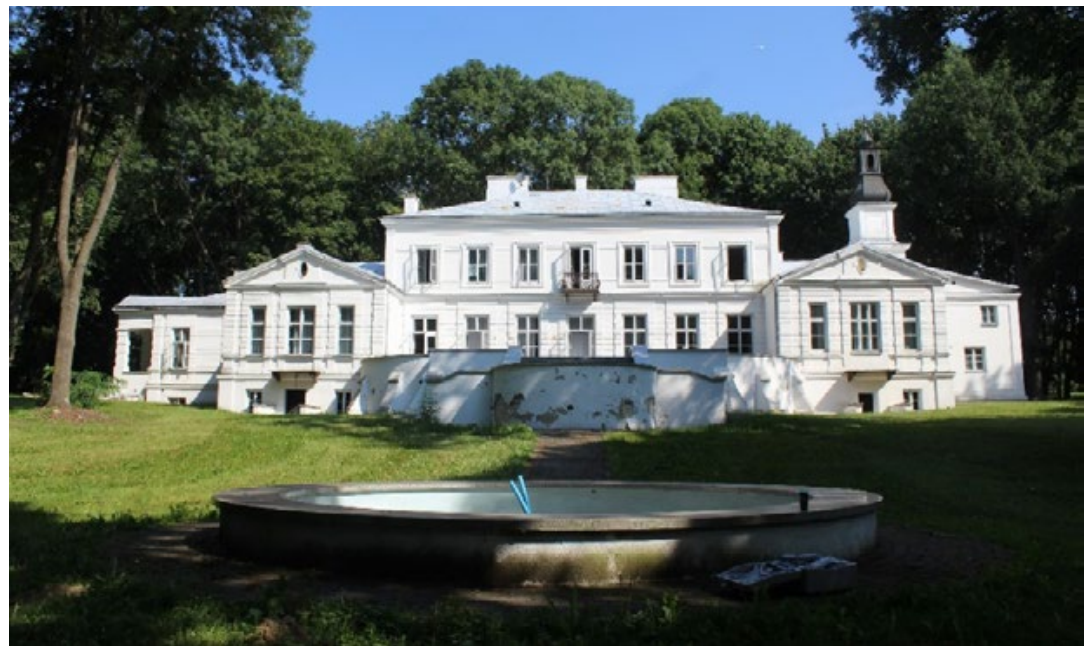

Fig. 2. South façade. (author's own photograph)

The palace is situated on the main axis of the complex, about $80 \mathrm{~m}$ away from the border with a farmyard. It is established on the projection close to an elongated rectangle on the east-west axis. The front of the building faces north. On the south side, on the axis of the palace there is a large semi-circular terrace with three-way symmetrical stairs and a semi-circular landing in the main axis (Fig. 3.). 


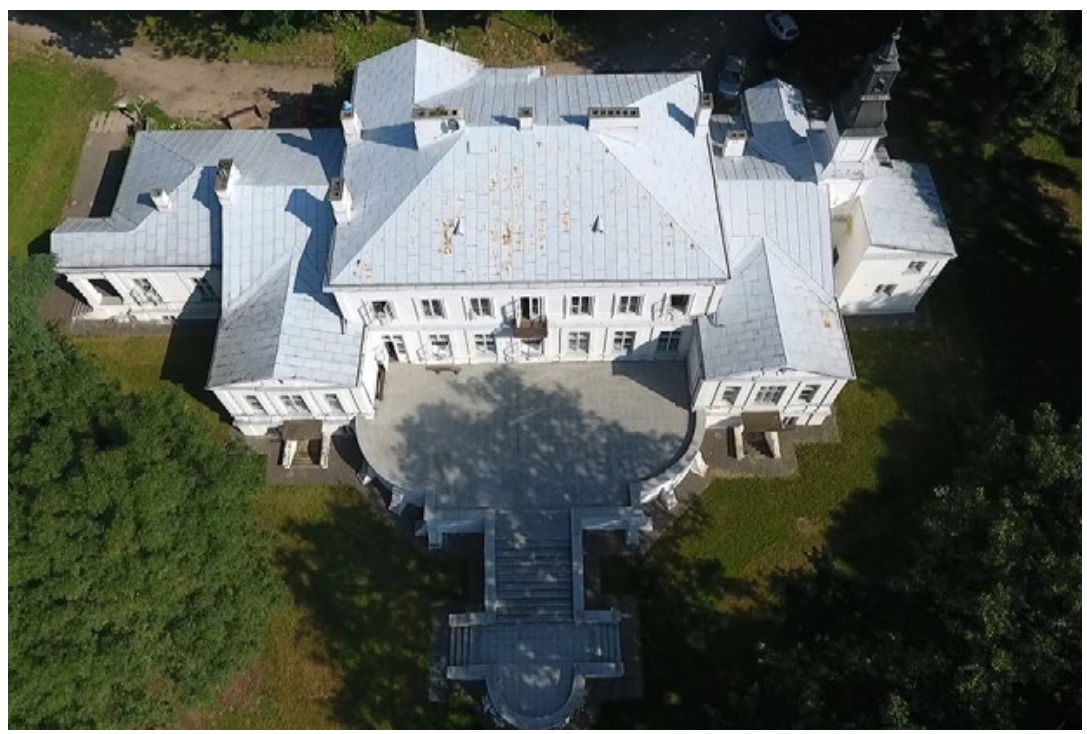

Fig. 3. Top view (author's own photograph)

Originally on a symmetrical plan: a body on a short rectangular plan, side wings on an L plan, a 3-storey tower on a square plan from the east and a more recent addition. The building is detached, brick, plastered and partially cellared. The façades show rustication at the level of the ground floor, cornices above each floor, topped with roof light flashing.

Above the main entrance, on the north side, there is a decorated steel roof and over it, the small balcony with a steel ornamented railing. Correspondingly, on the south side, there is the similar balcony over the terrace. From the south - on the side of the garden - above the entrances to the part with the basement, there are symmetrically decorated roofs with steel ornaments.

Multi-pitched roof is covered with steel sheet. Gutters and downpipes are visible on the façades. Rainwater from the roof slope is drained through gutters to drainage pipes hidden in the ground under the drainage band. Window carpentry is made of wood.

Inside the building, there are two staircases that connect the ground floor with the first floor, one staircase that provides access to the basement part and one staircase that leads to the first floor of the annex. The main staircase located at the main entrance is wooden with ornamentations on the railings and the well between the runs of the stairs. The second staircase is made of brick with a wooden railing and is located at the clock tower in the east part of the building. Staircase to the basement part is made of brick without visible decoration.

Rooms arranged in a row with aligned doors (in a system of enfilade) with a corridor on the axis of the west-east plan. There is a sewerage system in the building. Sanitary rooms are renovated and adapted to the current function of the building. Toilets are located on the ground floor level in the east wing (in the annex) and in the west wing of the building. Walls made of red brick are the basic structural element of the building. Window and door openings inside the building are decorated with cornices. In some rooms there are ornaments in the plaster by the upper lighting and in the wall and ceiling joints.

\section{The use of a point cloud during inventory}

One of the most important works performed during the inventory is measurements that need to be as accurate as possible. It is essential especially in the case of activities involving historical buildings. The inventory made in this way is both a detailed archival material as well as a contribution to subsequent activities aimed at the preservation of historical value of the building [Boron 2007].

Measurements performed with the use of modern laser scanning technology can reduce the risk of measurement error to a minimum. The data obtained with the device in the form of a point cloud (Fig. 4.) are used to create very precise inventory note. Thanks to this technology, it is possible to reproduce the existing building geometry taking into account the accurate architectural detail (Fig. 5.) in a three-dimensional space. Additionally, 
during the façade measurements, the measuring device performs a scan of the surrounding environment, such as an adjacent tree stand or area diversity. As a result, it gives current information on the development of the neighbouring area. The technology has been applied in the course of years and is becoming more and more widely used, e.g. for accurate measurement of afforestation [Liang 2016].
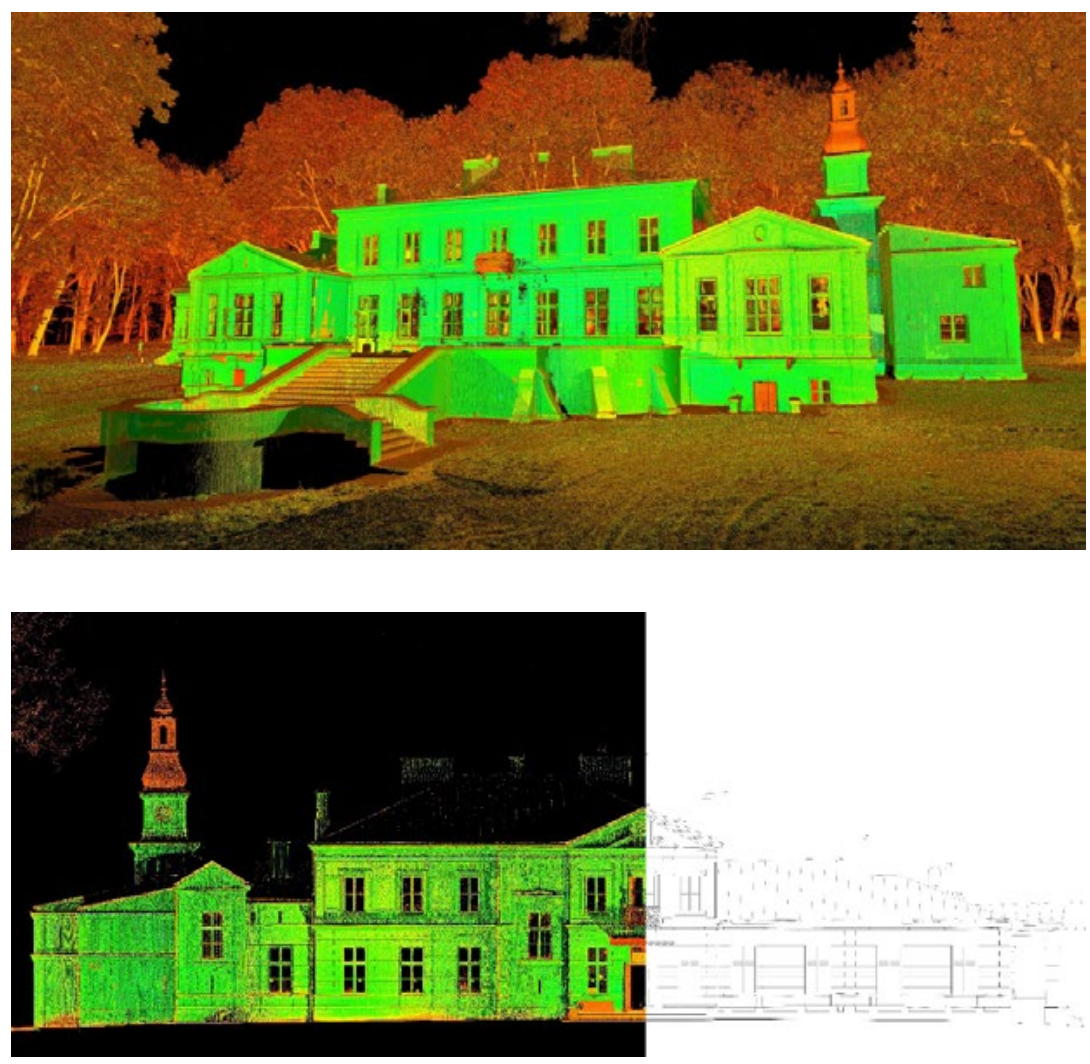

Fig. 4. Obtained point cloud with the Leica $\mathrm{C} 10$ (elaborated by the author)
Fig. 5. Overview of the façade development with the completed drawing (elaborated by the author)

This method also gives the opportunity to conduct a comparative analysis based on archival materials and to develop a detailed assessment of the technical condition of the facility. After generating a point cloud obtained from scanning the palace building, some elements were noticed which could be omitted with the use of the traditional method, i.e. different thickness of walls on subsequent floors and reference of their location in relation to each other. This is illustrated by the cross-section of the object generated in Leica Cyclone program (Fig. 6.). All deformations in the building's geometry are clearly visible and clear. Then $2 \mathrm{D}$ documentation was prepared based on the generated image (Fig. 7.)

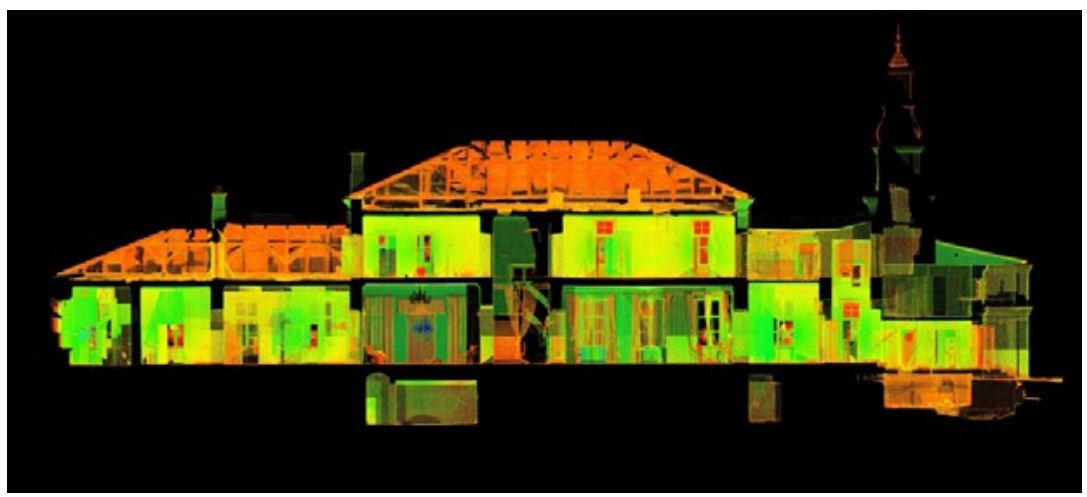

Fig. 6. Cross-section of an object generated from a cloud of points (elaborated by the author) 


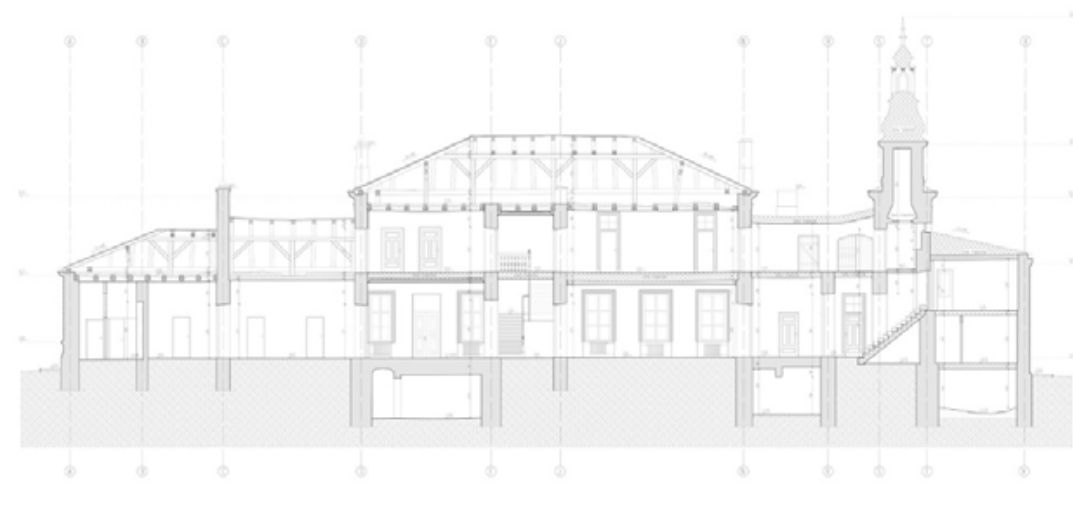

Fig. 7. Cross-section of the object based on a point cloud (elaborated by the author)

When working with the acquired point cloud, it was possible to transfer the actual state onto the paper version keeping the maximum accuracy of the building geometry. The following picture shows a comparison of a 3D scan generated in Leica Cyclone program with a drawing made on its basis representing the plan of the ground floor of the building (Fig. 8.).

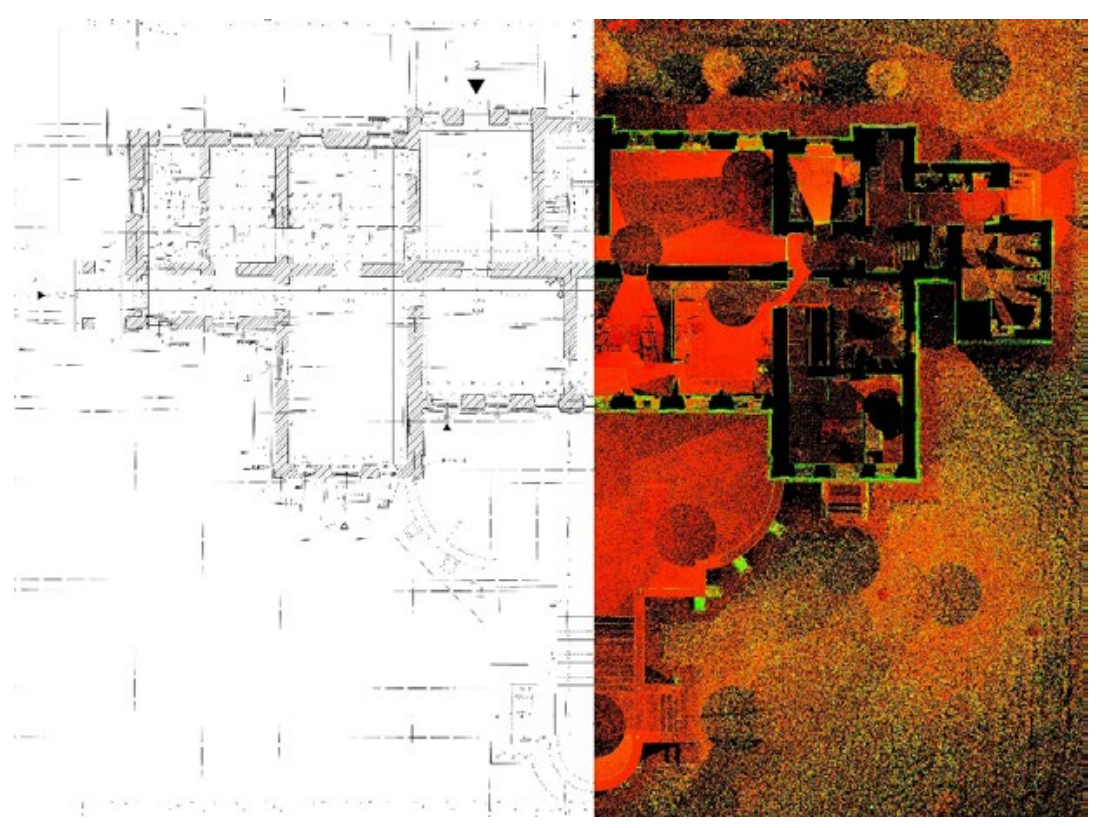

Fig. 8. Summary of the projection generated from the point cloud with the projection made on the basis of the cloud (elaborated by the author)

\section{Conclusions}

Measurement works using laser technology to scan objects into a 3-dimensional XYZ space are necessary for buildings that are complex in both spatial functional structure and façade composition. In these cases, laser scanning can be used to analyse building elements that are invisible or even impossible to catch by the traditional measurement methods. An important aspect here is also the analysis of materials from a point cloud in terms of the assessment of technical condition of a building. It enables to determine with a much greater accuracy stratification, cavities, cracks, corrosion or deflection of ceilings in each plane. The result of such works can then be precisely performed architectural inventory along with an assessment of the technical condition and, consequently, the course of actions aimed at the preservation of cultural assets.

A point cloud obtained with scanner measurements is in itself an important and valuable element in the architectural and preservation documentation. The obtained 2-dimensional inventory is the ultimate result 
of these measurements. The 3D model has the most important value here and can be used for later studies or planned conservation activities of a historical building. The BIM technology used in scanning of historical structures may be an important aspect of the agreement between owners, designers and conservators. Laser scanning is an important tool for this purpose.

\section{Literature}

[1] Boroń A., Rzonca A., Wróbel A., 2007. The digital photogrammetry and laser scanning methods used for heritage documentation. Pol. Tow. Przest., vol. V, part 8, p. 129-140.

[2] Decision on entry of the complex into the register of monuments of the Lublin Voivodeship No. KL-IV_7/3/71 of 16 October 1971.

[3] Filipowski S., 2018: Skaning laserowy w inwentaryzacji architektonicznej - stosowane rozwiązania i propozycja udoskonalenia, Laser scanning in architectural surveying - popular solutions and proposal for improvement. PUA 1/2018, p. 95-105.

[4] Kulig A., Nassery F., Filipowski S., Zieliński R., 2015: The use of BIM technology in modern methods of inventory and analysis of architectural monuments. Journal of Heritage Conservation, 42/2015, p. 33-43.

[5] Liang X., Kankare V., Hyyppä J., Wang Y., Kukko A., Haggrén H., Yu X., Kaartinen H., Jaakkola A., Guan F., Holopainen M., Vastaranta M., Terrestrial laser scanning in forest inventories ISPRS Journal of Photogrammetry and Remote Sensing 115/2016), p. 63-77. 